\title{
The Linear Relation between the Extent of Sexual Liberation and Level of Leisure Consumption among College Students in Western China
}

\author{
Yusu Qin ${ }^{*}$, Lin Lu \\ ${ }^{1}$ The School Culture and Social Development Studies of Southwest University, Chongqing, China \\ ${ }^{2}$ Center for Studies of Economic and Social Development, Southwest University, Chongqing, China \\ Email: "qyusu@yahoo.com, lulin@swu.edu.cn
}

Received 28 April 2016; accepted 31 May 2016; published 3 June 2016

Copyright (C) 2016 by authors and Scientific Research Publishing Inc. This work is licensed under the Creative Commons Attribution International License (CC BY). http://creativecommons.org/licenses/by/4.0/ c) (i)

\section{Abstract}

In order to explore the phenomenon that the leisure consumption has rapidly grown in China in recent years, a survey which is based on the hypothesis built by Werner Sombart that the secularization of love facilitates the endless consumption in the process of the formation of capitalism is conducted to prove that there is a linear relationship between the level of the leisure consumption and the extent of sexual liberation. The research through the network questionnaire survey on college students in colleges of Chongqing municipality, based on the completely random sampling method, gets 324 valid samples and analyzes them in the method of multiple stepwise regressions. As a result, the research proves that the leisure consumption of college students is remarkably correlated linearly with the self-judgment of sexual liberation $\left(\beta_{1}=0.101\right)$ and the number of sexual partners $\left(\beta_{7}=0.181\right)$ by controlling the noise variable including gender, age, college, major, educational attainment, single-parent family or not and religion. It's demonstrated that the extent of sexual liberation exactly raises the level of leisure consumption $\left(R^{2}=0.176\right)$.

\section{Keywords}

Leisure Consumption, Sexual Liberation, Youth, China

\footnotetext{
${ }^{*}$ Corresponding author.
}

How to cite this paper: Qin, Y.S. and Lu, L. (2016) The Linear Relation between the Extent of Sexual Liberation and Level of Leisure Consumption among College Students in Western China. Open Journal of Social Sciences, 4, 33-44. 


\section{Introduction}

In recent years, a lot of hot spots of Chinese residents' personal consumption behaviors attract our attention. The sharp increase of luxury consumption, online shopping displaying an amazing marketing value and popularity of overseas travel and fitness in gym are just a few of them. According to the recent researches China has already become the biggest customer in global luxury market. There was a phenomenon that Chinese generally spent $40 \%$ of their wealth on luxury consumption, which was unbelievably compared with the average level of globe, $4 \%$ actually [1]. In the field of mass consumption online shopping was playing a more and more important role, especially the Online Big Sale of Taobao in Nov.11 which made an amazing deal record in every year. On Nov.11 2015, only the transaction platform of Alibaba created a turnover of RMB 912.217 billion; compared with the RMB 571 billion in 2014, it raised 59.72\% [2]. And actually, just on Nov.11 2014, the turnover of RMB 571 billion has already set a world record of daily retail business transaction at the highest level that made the online purchasing power of Chinese residents attract the global attention [3]. Compared with commodity consumption, the service leisure consumption of Chinese residents does not show weakness. The increasing popularity of overseas travel and fitness in gym revealed the constantly rising pursuit of Chinese residents for leisure consumption [4]. On account of the mushrooming leisure consumption, it's necessary to explore the deeply mechanism of this phenomenon, which is significant for Chinese social transition.

This phenomenon is not unique in our human-being's history. The endless pursuit for leisure consumption had emerged in the process of the development of capitalism. One of the most prominent works, absolutely, is the great book Luxury and Capitalism (1913) by Werner Sombart. This classic gives us a unique insight into the luxurious consumption in that period of time. Of course, the leisure is definitely not luxury. But depending on the words of Sombart, "the luxury is any consumption that exceeding the basic cost" [5]. The luxury here is exactly a kind of leisure. In the analysis, Sombart suggests that "such a huge luxury phenomenon must be created by many environment factors work together, including wealth, sexual liberation, the attempt to achieve advantage for certain group, the preference for city life” [5]. And the secularization of love, resulting in the sexual liberation, actually, plays a shining role among them. He said: "The money spent on adultery is the largest spending on financers' accounts." “Our sex is exactly the origin of requirement of refined and increasing methods of the sensory stimuli, because the pleasures of sense are essentially the same with sexual pleasure. It's indubitable that the root cause which drives any kind of developments of luxury could be almost found out in sex impulse that show their function consciously or unconsciously” [5]. As a result, can we speculate that there are some psychosocial factors, like the sexual liberation improving our leisure consumption excepting the traditional economic factors?

Regretfully, in China, the relevant research was not too much. A lot of studies focus on sexual attitude and sexual behaviors but not on sexual liberation, not only on a macro level of society but also a micro level of person. A few existing studies on Chinese sexual liberation were almost based on survey research, and analyzed the feature of the sexual liberation of Chinese and influencing factors. For example, the network survey on sexual liberation and its influencing factors of Chinese unmarried youth by Tian Feng [6] and the investigation on the great change of Chinese sexual liberation after the reform and opening-up policy of China by Wu Luping [7]. Thus it can be seen that there was hardly any studies devoted into the relation between sexual liberation and leisure consumption in China. Compared with China, western had a long history on the study of sexual liberation. From the beginning of the $20^{\text {th }}$ century, especially the "sexual revolution" movement pushed the research on sexual liberation to the climax. In that period of time, researches generally promoted sexual freedom, emphasizing that to enjoy "sex" is a human right, which also, unfortunately, in later, led to a lot of social problems including the increase of divorce rate, young people involved into sex too early, the spread of STDs and HIV and so on [8]. Since the 1980s, western researches about sexual liberation have returned to emphasizing the seriousness of sexual relationship and the responsibility for sexual behaviors. A typical case of them was the research on the sexual liberation after people got married, which reflected the concerns over its serious consequences after the sexual revolution [9]. At present, under the background of "sex regression", researches on sexual liberation turned to several different paths. One of them focuses on the sexual liberation of lesbian, gay, bisexual and transsexual (LGBT). This kind of research generally applied the traditional topics onto these groups, like the research on the openness about sexual orientation and/or gender identity and its relationship to well-being and educational outcomes for LGBT students [10]. Other efforts were devoted into the survey about high-risk sexual behaviors and especially into the spread of HIV in the developing regions such as Asia, Africa and Latin America. These studies is generally demonstrated that those factors led to high-risk sexual behaviors including the 
lack of sexual knowledge, being conservative about sex or not and the personal life styles of local people, which mainly referred to alcohol abuse and drug dependence [11]-[13]. Among them, only the search which taken place in Madagascar conducted by Kirsten Stoebenauand her team discussed about the relation between leisure consumption and sexual behaviors. Their works paid attention to the association between modern goods, lifestyles and sexual behaviors among youth demonstrated that the open sexual behaviors in that area correlated with the fashionable lifestyles brought by globalization and, absolutely, related to the wealth and expenditures. But, he emphasized that it's the consumer's motivated sexual behaviors but not on the contrary [14].

Above all, the rapidly growth of leisure consumption is a non-ignorable phenomenon to China transforming society. The lack of the sensitive insight into the internal mechanism of this phenomenon may lead to squander and waste of the whole society, just like what Sombart had described. As to this phenomenon, understanding correctly and grasp efficiently could not only avoid emerging those catastrophic social problems but also guide consumption, boosting the domestic demand which was depressed for a long time [15]. Seeking the answer from the theory, Sombart's theory that the secularization of love facilitates the endless consumption may give us a good inspiration. The previous researches almost focused on the features and influence factors of this phenomenon and payed attention to analyzing these topics in certain groups or specific social problems. To regard impetus of sex it-self as a promoter to certain phenomenon have been neglected for a long time. Actually, the lack of the attention to the impetus of sex may become a significant obstacle for us to understanding and judging some existing outstanding social problems [16]. Especially, at present, the attention to the relationship between leisure consumption and sexual liberation is quite insufficiency. To explore this relationship will become very meaningful, not merely to better understanding the transformation of Chinese society but also to supplementing and perfecting the relevant theory. Therefore, this research hypothesis: There is a linear relation between the extent of sexual liberation and the level of leisure consumption.

\section{Method and Data}

\subsection{Sampling Frame}

The respondents of this survey were college students in Chongqing municipality. Chongqing as the youngest municipality directly under the central government of China economy develops rapidly. In 2012, Per Capita GDP was 38742.28 yuan, compared with other 31 provinces (municipalities and autonomous regions) ranked $13^{\text {th }}$ in China. (This rank didn't include Hong Kong Special Administrative Region and Macao Special Administrative Region) Household consumption level was 13,655 yuan, ranked $11^{\text {th }}$. And Per Capital Annual Living Expenditure of Urban Households was 14974.5 yuan, ranked $10^{\text {th }}$. This kind of economic entity that Per Capita GDP was in the national average level and consumption slightly higher was appropriate to be the survey area [17]. According to the related researches, income was associated with desire and impairment in other aspects of sexual function [18]-[20]. So, choosing college students whose income gap was small and relatively stable as the respondents could be able to control the error caused by income. The range of respondents' age of this survey supposed to be 18 - 28, and including junior college student, bachelor, master and doctor, which were drawn equally from the comprehensive university, medical university, finance and Economics University, engineering university, normal university, arts and sports college, totally 8.

\subsection{Sample Size Estimation}

This research used completely random sampling method and chosen a formula which was used in an investigation about premarital sex-related knowledge, attitudes and behaviors, and HIV/AIDS of students in Nanning by Guangxi Medical University (GXMU) (Formula 1).

$$
n=\frac{Z_{1-\alpha / 2}^{2} \frac{P(1-p)}{\delta^{2}}}{2}
$$

According to the study by GXMU, the incidence of sexual behaviors in college students was $P=27.5 \%$. Setting $\alpha=0.05$ ( $\alpha$ : The limit of statistical significance) and Margin of error $\delta=5 \%$. Sample size $n=306$ after the calculation [6].

\subsubsection{Operationalization}

This research was based totally on cross-sectional studies to reveal the internal relation between the sexual libe- 
ration extent and the leisure consumption level of college students in Chongqing municipality. Wu Luping, the dean of Youth Work Department at China Youth University of Political Sciences, generalized the sexual liberation into two layers: the acceptance to sexual knowledge and the openness to sexual behaviors [7]. The point of this research was measuring sexual behaviors (objective aspect), totally 4 variables (Table 1 ). And in order to access more closely to the truth, we added self-rating items about their own sexual liberation level and sexual desire (subjective aspect), totally 4 variables. Some scholars concluded that the leisure consumption is an activity which consume both material and mental leisure products. This activity could be induced into four layers: the consumption of satisfying the physiological need, healthy entertainment, the self-development and fulfilling the mental demands [21]. This time, considering utility, this research just focus on two of them: the consumption satisfied the physiological need and the consumption satisfied the healthy entertainment. We chose the items including eating, clothing, housing, traveling and some other leisure consumptions like consuming in night club, café and cinema, as the objective dependent variables in leisure consumption part. Some of them, like eating, clothing, housing and traveling have been involved in this questionnaire for these items were been defined as the basic approach to get a luxury life by Thorstein Veblen in his The Theory of the Leisure Class [22]. And the others, such as consuming in night club, café and cinema were involved for these are the major choices in college students' daily leisure life. These totally 11 variables measured by asking them their average times they spent and the range of the expenses. Consistent with sexual liberation side, we also added self-rating items about their own judgment of leisure consumption, totally 3 variables. Both two aspects consist of 22 variables. At the same time, another 7 items including the gender, age, university, major, educational attainment, single-parent family or not and religious faith would be set as the control variable, because the previous researches demonstrated that the differences on these items would make the sexual attitude and behaviors or their leisure consumption different [23]-[25]. Above all, the entire questionnaire which was composed of 22 variables was presented and scored as five-point scale (Table 1).

Table 1. Table of variables.

\begin{tabular}{|c|c|c|}
\hline & Subjective & Objective \\
\hline Sexual liberation & $\begin{array}{l}\text { S1: The self-judgment of sexual } \\
\text { liberation }\end{array}$ & S5: The times having sex in last 12 months \\
\hline \multirow[t]{3}{*}{ (Independent variables) } & $\begin{array}{c}\text { S2: The self-judgment of extent of } \\
\text { sexual needs }\end{array}$ & $\begin{array}{l}\text { S6: The times having one night stand in last 12months (including the } \\
\text { purchase for sex) }\end{array}$ \\
\hline & S3: The ideal sexual frequency & S7: The number of sexual partners in last 12 months \\
\hline & $\begin{array}{l}\text { S4: The frequency of the sexual } \\
\text { fantasy }\end{array}$ & $\begin{array}{l}\text { S8: The highest number of the sexual partners at the same time in last } \\
\qquad 12 \text { mouths }\end{array}$ \\
\hline Leisure consumption & $\begin{array}{l}\text { C1: The self-judgment of the size of } \\
\text { the leisure consumption }\end{array}$ & C4: The expenses on the outside dinner* ${ }^{* *}$ \\
\hline \multirow[t]{10}{*}{ (Dependent variables) } & $\begin{array}{l}\text { C2: The proportion of the leisure } \\
\text { consumption per-month }\end{array}$ & C5: The expense on the snack per-month \\
\hline & $\begin{array}{l}\text { C3: The suitability of the size of the } \\
\text { leisure consumption }\end{array}$ & C6: The expense on the clothing every quarter \\
\hline & & C7: The average price of the clothing \\
\hline & & C8: Travel times in a year (including excursion and suburban travel) \\
\hline & & C9: The average expenses of those journey \\
\hline & & $\begin{array}{c}\text { C10: The hotel price of independent choice during a business trip or } \\
\text { journey }\end{array}$ \\
\hline & & C11: The expense on sports in a year \\
\hline & & C12: The average times going to the cinema per-month \\
\hline & & C13: The average times going to the nightclub per-month \\
\hline & & C14: The average times going to the Café per-month \\
\hline
\end{tabular}

\footnotetext{
${ }^{*}$ Variable S1 and S2 appeared in the level of 1 to 5 increases gradually. According to self-rating respondents selected the corresponding level. ${ }^{* *}$ College students usually eat in college canteen. These canteens are subsidized by government. Therefore, the food they offered is cheap and meets the basic needs. So, eating out of the college campus belong to the leisure consumption.
} 
In the aspect of subjective variables, due to the judgment, these options that from 1 to 5 sexual liberation level increases gradually would differs from respondents to respondents, so, questionnaire offered the reference standards for each option. For example, Level 1: Level (option) 1 is extremely conservative, firmly opposed to themselves or others having premarital sex. Level 5: Level (option) 5 is fully open, deeming sex is just sex, and we should enjoy the sex without any restriction. Level (option) 2 and level (option) 4 were the series of equal interval options from level 1 to level 5. Variable S3 asked respondents' ideal frequency of sex, like "4 times per-month" or "3 times a week". Generally, it's impossible for respondents to accurately answer the value of their frequency of the sexual fantasy. Therefore, variable S4 was presented like an item of conventional fivepoint scale, asking respondents their sexual fantasy frequency is "almost do not" or "occasionally" and so on. From variable S5 to variable S8, these variables all reflected the objective behaviors, which were quantifiable but difficult to making the values accurate. So, we presented them as times or intervals, for instance," 10 to 30 times" or "3 to 5 sexual partners". Variable C1 and variable C2 also were presented like an item of conventional five-point scale, just like asking respondents their leisure consumption was "relatively large" or "moderately", etc. Because of the difficulty for respondents to remember their expenditure accurately, variable C4 to variable C11 were presented by asking respondents their expenditure interval, like "the hotel price of independent choice is range from 100 yuan to 200 yuan or from 200 yuan to 300 yuan”. Finally, from C12 to C14, which were almost involved into the daily leisure activities and calculated monthly that meant its frequency wouldn't be too high, therefore, respondents, usually, could remember them clearly. These variables were presented by asking respondents the times of their leisure activities, like "go to the nightclub 3 times per-month" or "go to the nightclub 4 times per-month", etc. In the end, all items would be transformed into the numerical variables of 1 to 5 score for statistical analysis.

\subsubsection{The Reliability and Validity of the Questionnaire}

This time, Cronbach's alpha was performed as index of reliability during the study (Formula 2).

$$
\propto=(n / n-1)\left(1-\sum S_{j} / S_{t}\right)
$$

And after testing the 39 trial testing samples, we got the $\alpha=0.81$ on level of leisure consumption and $\alpha=0.82$ on the extent of sexual liberation demonstrated that the reliability of this questionnaire is quite available that can be used as a research tool (Table 2).

The designing process of the questionnaire was suggested by experts and scholars, and the choice of each item follows the relevant concepts, definitions and theoretical frameworks, which have built a good content validity.

\subsubsection{Data Collecting}

This survey taken the completely random sampling method, and data was collected by network questionnaire survey. Firstly, we imported the questionnaire into a third party online survey platform called Sojump

(http://www.sojump.com/), which is a well-known questionnaire survey platform in China, then, producing a network questionnaire in this platform. This platform generated a URL (an internet address) that could be sharing on the campus BBS and Baidu post bar of every university to issuing questionnaire. As if the respondents, the college students surfing these BBS, clicked the URL they could visit the network questionnaire and fill out questionnaire online. After completing the questionnaire, all data will be auto-saved immediately by Sojunp. At last, we pasted the data from Sojump on the IBM statistics 2.0 to go on a data analysis.

\subsubsection{Method of Analysis}

After collecting enough samples, we transformed every option into numeric variables of 1 to 5 scores, separately calculating the mean value of leisure consumption dimension and the mean value of sexual liberation dimension, and then, creating two new variables, the mean value of leisure consumption and the mean value of sexual liberation. Through drawing a scatter diagram to make sure the linear relation of these tow variables, we analyzed the linear relation between the new variable of leisure consumption and eight independent variables by multiple linear regression, and finally, getting the regression models.

\section{Result}

After the actual sampling, the overall samples content is 324 consisting of 173 males which account for 53.4\% 
Table 2. Reliability statistics.

\begin{tabular}{ccc}
\hline & Cronbach's alpha & N of items \\
\hline Leisure consumption dimension & 0.814 & 14 \\
Sexual liberation dimension & 0.815 & 8 \\
\hline
\end{tabular}

and 151 females which account for $46.6 \%$, demonstrating a relatively balance proportion of men and women. The major of these informants' shows that the science and engineering account for a large proportion, $45.4 \%$ compared with $29.0 \%$ of Humanities \& Social science and $25.6 \%$ of Sports \& Arts. Family structure shows that whole family account for almost totality, and single-parent family just $7.1 \%$ slightly. Non-religious faith form the majority of overall, 81.8\% distinguished from the rest, like Buddhism, Christian, Taoism and Islam which separately account for $13.0 \%, 3.1 \%, 1.5 \%$ and $0.6 \%$. The above two variables are effectively controlled by the interference of religious faith and single-parent families effect on validity (Graphs 1-4).

As expected, the actual sampling ages range from 17 years old to 30 , which is as expected. And because the mean value was 21.15 , median was 21 and mode was 20 , this distribution approximates the normal one demonstrated an excellent sampling (Graph 5).

The distribution of universities basically meets the design of sampling frame. The comprehensive universities, Chongqing University (CQU) and Southwest University (SWU), account for 26.0\%. The Chongqing Normal University (CQNU) account for 25.3\%. And the Chongqing Jiaotong University (CQJTU), Chongqing Technology and Business University (CTBU) and Sichuan Fine Arts Institute (SCFAI) account for 16.0\%, 13.0\% and 12.7\% respectively. The Medical Universities, Third Military Medical University (TMMU) and Chongqing Medical University (CQMU), account for 7.1\%. All data match with the distribution of each university on population and profession (Table 3).

\section{Linear Test and Model}

After calculating the mean of the all 14 dependent variables, we formed a new variable called "the average of the leisure consumption level" and calculated the mean of 8 independent variables, formed a new variable called "the average of sexual liberation extent", making a scatter plot about the Mean of the leisure consumption level and sexual liberation extent, we see the linear relation of these two variables (Graph 6). But, to reveal which one contributes to the variation of the dependent variable among the 8 independent variables, we need to test it by multiple regression tests. The correlation was analyzed by multiple linear stepwise regressions and produced two models. Model 1 contains the variable S7 "The number of sexual partners in last 12 months", and its determination coefficient $\mathrm{R}^{2}=0.144, \beta_{7}=0.254$. And the analysis of variance was obviously significant. Model 2 accepted the variable S7 "The number of sexual partners in last 12 months" and variable S1 "The self-judgment of sexual liberation”. Determination Coefficient $\mathrm{R}^{2}=0.176, \beta_{7}=0.181, \beta_{1}=0.101$, analysis of variance was also significant, demonstrating that the addition of "the sexual liberation" reduced the contribution of the number of sexual partners to leisure consumption level, declining 0.073 percentage points. The optional model was Model 2 , which explained the $17.6 \%$ of the total variances. While the values of Tol are all close to 1 and the values of VIF are all located in the range of 1 to 10 , we believe that the effect of multicollinearity among variables is eliminated in the regression model and an ideal mathematical model is constructed (Table 4).

The results confirmed the hypothesis that there is a linear relation between the extent of sexual liberation and the level of leisure consumption in college students of Chongqing municipality. But we see the explanatory power is weak. Seeking for the reason we believe it carried out by the sample selecting that chose college students who are indeed an accessible one and efficiently control the error caused by income, lacking the spending power and relatively hard to practice the sexual behaviors.

In all 324 samples, $77.8 \%$ reported their leisure consumption just occupy the $0 \%-40 \%$ of their total expenditure. And, another research conducted in Shandong province also shows the majority of the college students, $27.1 \%$ accounted for all 720 samples, spend 500 - 1000 Yuan per-month, and 92.78\% of these money come from the family support [26]. Some samples show that the high score group on the items of "self-judgment of the sexual liberation extent" and "self-judgment of sexual desire", on the contrary, gets a lower score in the realization of sexual behaviors. Through the T-test of the TP (total score) of the two sub-scales of sexual liberation, subjective scale consisting of 4 items and objective scale also consisting of also 4 items, we get the significant 


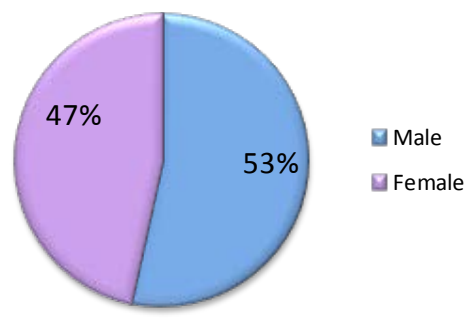

Graph 1. Gender.

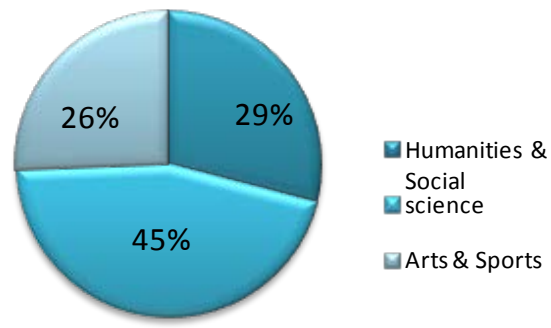

Graph 2. Major.

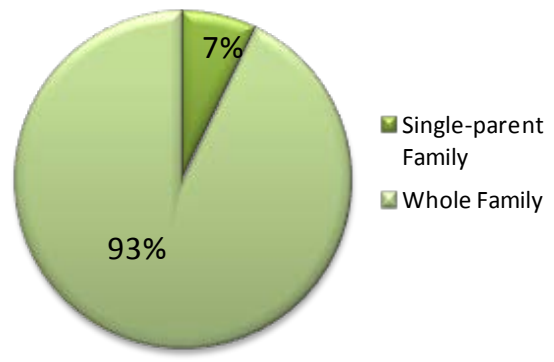

Graph 3. Single parent or not.

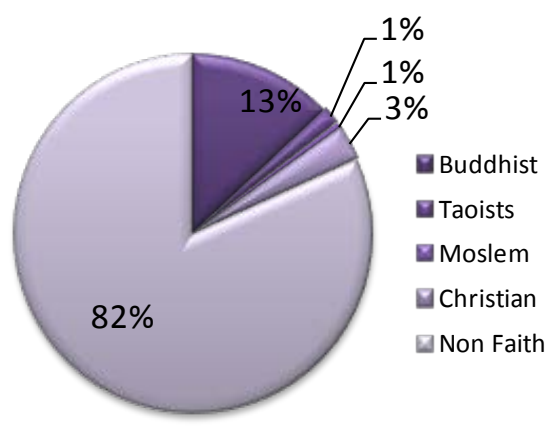

Graph 4. Religious faith.

difference between the subjective wants of their sexual liberation and the real implementation of their sexual behaviors. $t_{0.05 /(2.323)}=26.22, P=0.00<\alpha=0.05$ (Table 5 ).

\section{Discuss}

This result revealed that because of the limited income of college students, their consumption power is quite inadequate, and the campus life, especially the social role as a student, leads that most of these subjects are single, 49.5\%, according to a survey of 300 college students from Yunnan province [27]. And, they are also lack the ability and opportunity to access sexual behavior. According to the recent researches around China, the incidence of sexual behaviors among college student is about $10 \%$ [28]-[30]. We believe that all of them led to the 


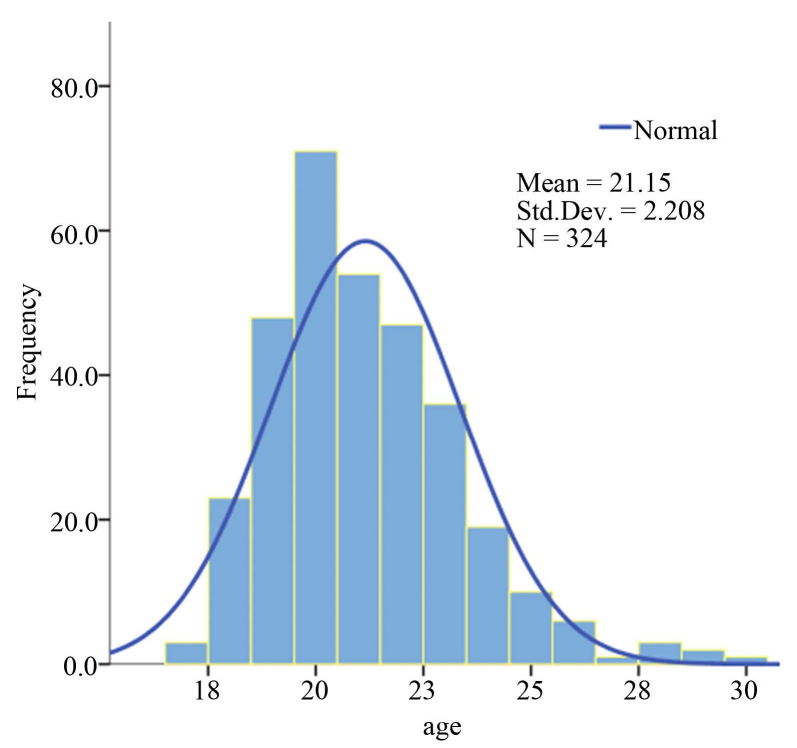

Graph 5. The age distribution.

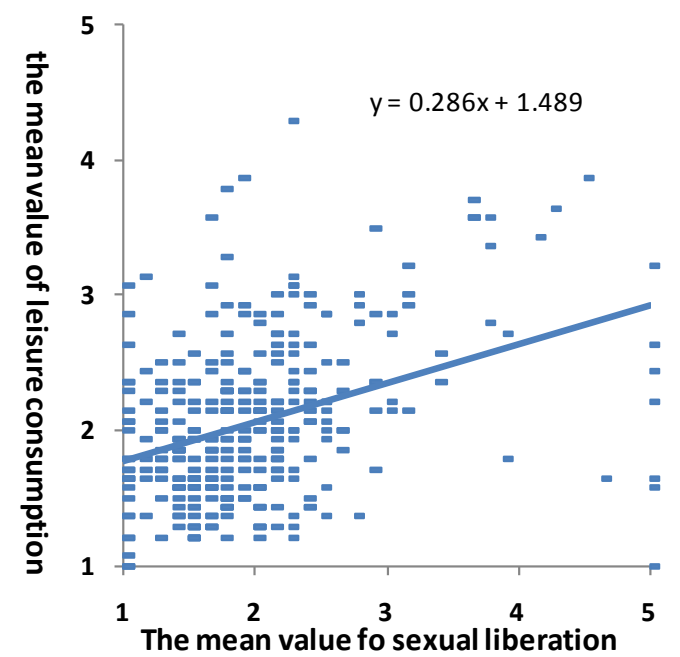

Graph 6. Catter plot of the leisure consumption level and sexual liberation extent.

relatively weak explanatory power of these survey data. Another research demonstrated, consistently, compared with college students, that worker participants got a higher score on liberal toward sex [31].

Only the "The self-judgment of the sexual liberation" in subjective self-rating scale and "The numbers of sexual patterns in last 12 month" in objective self-rating scale were accepted in the model which eliminated the rest of other 6 independent variables. Absolutely, "The self-judgment of the sexual liberation" in subjective selfrating scale is the leading indicator in independent variables, and their outlining significance on explaining the variation of dependent variables is verified the reality of the hypothesis that there is a liner relation between the extent of sexual liberation and the level of leisure consumption.

The reason why these are variables, like "The self-judgment of their own sexual needs", "The ideal sexual frequency" and "The frequency of the sexual fantasy", were excluded from the final model, probably, is the different conceptual understanding about sexual needs and sexual fantasy and not sure the real values of ideal frequency of sex for their unstable sexual behaviors. "The numbers of sexual partners in last 12 month" as the leading indicator of sexual liberation was accepted by the model also proved the reality of hypothesis on the behavioral aspect. But, on account of ignoring the weight of parameters during the questionnaire designing period, 
Table 3. The distribution of Univ. and educational attainment.

\begin{tabular}{ccccccc}
\hline & & Total & Bachelor & Master & Doctor & The rest \\
\hline \multirow{2}{*}{ Comprehensive Univ. } & CQU & $19(5.9)$ & $7(2.7)$ & $11(22.4)$ & $1(12.5)$ & $0(0.0)$ \\
& SWU & $65(20.1)$ & $55(21.6)$ & $4(8.2)$ & $1(12.5)$ & $5(45.5)$ \\
Medical Univ. & TMMU & $7(2.2)$ & $1(0.4)$ & $1(2.0)$ & $3(37.5)$ & $1(9.1)$ \\
& CQMU & $16(4.9)$ & $6(2.4)$ & $8(16.3)$ & $2(25.0)$ & $0(0.0)$ \\
Finance \& Economics Univ. & CTBU & $42(13.0)$ & $36(14.1)$ & $1(2.0)$ & $1(12.5)$ & $4(36.4)$ \\
Engineering Univ. & CQJTU & $52(16.0)$ & $44(17.3)$ & $7(14.3)$ & $0(0.0)$ & $1(9.1)$ \\
Normal Univ. & CQNU & $82(25.3)$ & $74(29.0)$ & $8(16.3)$ & $0(0.0)$ & $0(0.0)$ \\
Arts \& Sports Univ. & SCFAI & $41(12.7)$ & $32(12.5)$ & $9(18.4)$ & $0(0.0)$ & $0(0.0)$ \\
Total & & $324(100)$ & $255(100)$ & $49(100)$ & $8(100)$ & $11(100)$ \\
\hline
\end{tabular}

Notice: in parentheses is the percentage.

Table 4. Coefficients ${ }^{\mathrm{a}}$.

\begin{tabular}{|c|c|c|c|c|c|c|c|c|}
\hline & \multirow{2}{*}{ Model } & \multicolumn{2}{|c|}{$\begin{array}{l}\text { Unstandardized } \\
\text { coefficients }\end{array}$} & \multirow{2}{*}{$\begin{array}{c}\text { Standardized } \\
\text { coefficients } \\
\text { Beta } \\
\end{array}$} & \multirow{2}{*}{$\mathrm{t}$} & \multirow{2}{*}{ Sig. } & \multicolumn{2}{|c|}{$\begin{array}{l}\text { Collinearity } \\
\text { statistics }\end{array}$} \\
\hline & & B & Std. Error & & & & Tolerance & VIF \\
\hline \multirow{3}{*}{1} & (Constant) & 1.658 & 0.062 & & 26.696 & 0.000 & & \\
\hline & $\begin{array}{l}\text { The number of sexual partners in last } \\
12 \text { months }\end{array}$ & 0.254 & 0.035 & 0.379 & 7.360 & 0.000 & 1.000 & 1.000 \\
\hline & $\mathrm{R}=0.379$ & $\mathrm{R}^{2}=0.114$ & $F=54.177$ & Sig $=0.000$ & & & & \\
\hline \multirow{4}{*}{2} & (Constant) & 1.513 & 0.073 & & 20.589 & 0.000 & & \\
\hline & $\begin{array}{l}\text { The number of sexual partners in last } \\
12 \text { months }\end{array}$ & 0.181 & 0.040 & 0.270 & 4.543 & 0.000 & 0.728 & 1.375 \\
\hline & The self-judgment of sexual liberation & 0.101 & 0.029 & 0.210 & 3.538 & 0.000 & 0.728 & 1.375 \\
\hline & $\mathrm{R}=0.420$ & $\mathrm{R}^{2}=0.176$ & $\mathrm{~F}=34.315$ & Sig $=0.000$ & & & & \\
\hline
\end{tabular}

${ }^{\mathrm{a}}$ Dependent variable: Average of consumption level.

Table 5. Paired samples test.

\begin{tabular}{|c|c|c|c|c|c|c|c|c|}
\hline & \multicolumn{5}{|c|}{ Paired differences } & \multirow{3}{*}{$\mathrm{t}$} & \multirow{3}{*}{$\mathrm{df}$} & \multirow{3}{*}{$\begin{array}{c}\text { Sig. } \\
\text { (2-tailed) }\end{array}$} \\
\hline & \multirow{2}{*}{ Mean } & \multirow{2}{*}{$\begin{array}{c}\text { Std. } \\
\text { deviation }\end{array}$} & \multirow{2}{*}{$\begin{array}{l}\text { Std. error } \\
\text { mean }\end{array}$} & \multicolumn{2}{|c|}{$\begin{array}{l}95 \% \text { confidence interval of } \\
\text { the difference }\end{array}$} & & & \\
\hline & & & & Lower & Upper & & & \\
\hline $\begin{array}{l}\text { Subscale score of the subjective } \\
\text { sexual liberation - Subscale score } \\
\text { of the sexual behavior }\end{array}$ & 3.97531 & 2.72916 & 0.15162 & 3.67702 & 4.27360 & 26.219 & 323 & 0.000 \\
\hline
\end{tabular}

some indicators what could more valid represented the sexual liberation of a society, like "The times having one night stand in last 12 month” and “The highest number of the sexual partners in last 12 months”, wouldn’t reflect their effects. Among the overall valid samples, those who have ever had one night stand account for $14.5 \%$ and had two sexual partners or above at the same time account for $8.9 \%$, even had three or more sexual partners at the same time still account for $2.8 \%$. That means the sexual liberation extent was being severely underestimated. Another research conducted in Fujian province demonstrate that among all 1056 participants, 18.9\% admitted to having had one-night stand experience and $72.7 \%$ of students that were surveyed showed comprehension and tolerance to others on one-night stand [32]. 


\section{Limitations}

The questionnaire was not designed very excellent yet, and especially the dependent variables are not adequate to allow more affluent analysis. For example, there are just two models accepted and the most valid one just accepted two variables from the all 8 variables. More details are needed for a deep research to reveal the relation that is the matter for our further work. And also there are some uncontrolled deviation coming from self-reports of consumption and sex, because men prefer to exaggerate their sexual activity and women, exactly, sometimes under-report [33].

Secondly, the sample is not the most suitable one, neither on the consumption nor on sex. The natural limitations of college students reduce the validity of this study. It's recommended that further research on the working men should give us a chance to know whether there is different or not.

Third, this study was conducted in Chongqing municipality, which is the youngest one among the China's four municipalities directly under the central Government, and the other three are shanghai, Beijing and Tianjin [34]. This history of immigration and multi-culture may be shaping it more inclusive and free, which make it not appropriate to generalize the result to the whole country.

\section{Conclusions}

At present, the rapidly growth of leisure consumption in China is not a fortunately historical coincidence. To explore the reason, we cannot ignore the psychosocial factors, especially the effects of impetus of sex on human behaviors which require us to moderately guide and take use of it.

Relying on a third party network platform to disturb the self-designed questionnaire, this research obtains 324 valid samples that come from colleges including comprehensive university, finance and economic university, engineering university, normal university, medical college and art \& sports colleges. After controlling the noise variables including age, gender, major, single-parents family or not and religion, we then analyzed the data in the method of multiple stepwise regressions. Results demonstrate the positive linear relation between sexual liberation and leisure consumption. Especially the "self-rating on their sexual liberation" and the "number of their sexual partners" affect their leisure consumption positively. Besides, it also shows that, generally, the leisure consumption of college students is still at a low level and there is a significant discrepancy between the subjective sexual desire and objective sexual behaviors. In addition, the results also reveal the phenomena like onenight-stand and multiple sexual partners existing in college campus and not rare. To seek the reason, we believe the lack of income resource, especially, in China, the living expenses of college students basically come from parents and, apparently, wouldn't be very abundant to prevent the college students to go on the leisure consumption. Otherwise, the tension between sexual desire and sexual behaviors of college students roots in the college campus life. In China, college students mainly live in dormitory where usually a room applies for 4 students or more that restrains our respondents to have sex. Moreover, as said above, the low income reduces the probability of college students to get a sexual satisfaction from other channels. Why are we must focus on this tension, just because it may be also affect other social problems, for instance, the current outstanding problems like college students' mental health and interpersonal conflict. And, facing the problem like internet addition, could we speculate that there is an existence of impetus of sex projecting into the virtual world? The researches with attention of the tension would help us, from another perspective, to better understand those problems which, until now, are still fuzzy in front of our eyes. Furthermore, we must pay more attention to the quiet growth of one-nightstand and multiple sexual partners, or it will bring social problems like the spread of HIV and STDs as well as what happened after the "sexual liberation". What's more, it will also cause the ethics problems conflicting with the traditional Chinese conception of marriage and family.

For the level of leisure consumption increasing with the extent of sexual liberation, seeking the root, maybe, Werner Sombart said "Our sex is exactly the origin of requirement of refined and increasing methods of the sensory stimuli, because the pleasures of sense are essentially the same with sexual pleasure”.

Impetus of sex is controlling our pursuit of sensory world by some certain mechanism. And, actually, the leisure consumption is definitely embedded in our sensory world. In China, the phenomenon like the rapid expansion of luxury market, the amazing online shopping carnival, the nationwide popular of fitness in gym and overseas travel may be, at first or superficially, irrelevant. But, precisely these consumption phenomena seeming unrelated are affected and promoted by the impetus of sex. 


\section{References}

[1] Zhou, P., Yan, H.Z. and Zhang, S.J. (2014) Luxury Consumption: A Contest for Status Ranking. Economic Research, S1, 168-175.

[2] Information, C.C. (2015) Tmall Sales in 91.2 Billion in Nov.11 2015. http://www.askci.com/news/chanye/2015/11/12/02421u5a0.shtml

[3] Qin, Z. (2015) The Online Big Sale of Taboo in Nov.11: How to Deal with It in 2005? Battlefront of Thought, S1, 2628.

[4] Wu, J. and Zhou, D. (2015) Chinese National Tourism Administration for the Foreign Travel Agencies New Association.

[5] Sombart, W. (2005) Luxury and Capitalism. Shanghai Century Publishing Group, Shanghai.

[6] Tian, F. (2007) China's Unmarried Youth Sexual Liberation and Influencing Factors. Youth Studies, 11, 30-35.

[7] Wu, L. (1993) Sexual Openness Extent Survey of Chinese Youth. Youth Studies, 11, 19-22.

[8] Jiang, C. and Li, S. (2013) Modern and Contemporary Western Sex Research: From Axiology Perspective. Theory and Modernization, 5, 29-33.

[9] Rubin, A.M. and Adams, J.R. (1986) Outcomes of Sexually Open Marriages. The Journal of Sex Research, 22, 311319. http://dx.doi.org/10.1080/00224498609551311

[10] Kosciw, J., Palmer, N. and Kull, R. (2015) Reflecting Resiliency: Openness about Sexual Orientation and/or Gender Identity and Its Relationship to Well-Being and Educational Outcomes for LGBT Students. American Journal of Community Psychology, 55, 167-178. http://dx.doi.org/10.1007/s10464-014-9642-6

[11] Diaz-Sotelo, O. (2010) Knowledges, Attitudes and Practices in University Students about Sexual and Reproductive Health and HIV/AIDS in Bogotá D.C., Colombia. Retrovirology, 7, 1-1. http://dx.doi.org/10.1186/1742-4690-7-S1-P115

[12] Adhikari, R. and Tamang, J. (2009) Premarital Sexual Behavior among Male College Students of Kathmandu, Nepal. BMC Public Health, 9, 1-9. http://dx.doi.org/10.1186/1471-2458-9-241

[13] Mathewos, B., Birhan, W., Kinfe, S., et al. (2013) Assessment of Knowledge, Attitude and Practice towards Post Exposure Prophylaxis for HIV among Health Care Workers in Gondar, North West Ethiopia. BMC Public Health, 13, 16. http://dx.doi.org/10.1186/1471-2458-13-508

[14] Stoebenau, K., Nair, R.C., Rambeloson, V., et al. (2013) Consuming Sex: The Association between Modern Goods, Lifestyles and Sexual Behaviour among Youth in Madagascar. Globalization and Health, 9, 13. http://dx.doi.org/10.1186/1744-8603-9-13

[15] Xiao, H. (2010) Analysis of China's Current Consumption-Based on Perspective of Income Distribution Policies. Southwestern University of Finance and Economics.

[16] Freud, S. (1962) Three Essays on the Theory of Sexuality. Basic Books, New York.

[17] NBS (2015) National Datas. National Bureau of Statistics of China.

[18] Beutel, M.E., Stobel-Richter, Y. and Brahler, E. (2008) Sexual Desire and Sexual Activity of Men and Women across Their Lifespans: Results from a Representative German Community Survey. BJU International, 101, 76-82.

[19] Ghalayini, I.F., Al-Ghazo, M.A., Al-Azab, R., et al. (2010) Erectile Dysfunction in a Mediterranean Country: Results of an Epidemiological Survey of a Representative Sample of Men. International Journal of Impotence Research, 22, 196-203. http://dx.doi.org/10.1038/ijir.2009.65

[20] Zhang, H.P., Fan, S. and Yip, P.S.F. (2015) Sexual Dysfunction among Reproductive-Aged Chinese Married Women in Hong Kong: Prevalence, Risk Factors, and Associated Consequences. Journal of Sexual Medicine, 12, 738-745. http://dx.doi.org/10.1111/jsm.12791

[21] Wang, Q. (2005) Leisure Economy. China Renmin University Press, Beijing, 246.

[22] Veblen, T. (1899) The Theory of the Leisure Class-An Economic Study of Institutions. Oxford University Press, New York, 107-177.

[23] Rodgers, J.L. (1983) Family Configuration and Adolescent Sexual-Behavior. Population and Environment, 6, 73-83. http://dx.doi.org/10.1007/BF01362288

[24] Ahrold, T.K. and Meston, C.M. (2010) Ethnic Differences in Sexual Attitudes of US College Students: Gender, Acculturation, and Religiosity Factors. Archives of Sexual Behavior, 39, 190-202. http://dx.doi.org/10.1007/s10508-008-9406-1

[25] Coe, K. and Palmer, C. (2011) Low Sex Cultures, Religious Moral Traditions, and Evolutionary Theory Cultural Mechanisms for Influencing Male Sexual Behavior. Journal of Anthropological Research, 67, 557-572. 
http://dx.doi.org/10.3998/jar.0521004.0067.403

[26] Feng, L. (2014) Survey and Analysis of Consumption of Contemporary University Students. Shandong University, Jinan.

[27] Yu, P. and Zhao, W. (2004) An Investigation of Sexual Attitudes, Morality Behaviors of College Students in Yunnan Province. Journal of Yunnan Normal University, 36, 111-116.

[28] Liu, T., Lin, C., Huang, M., et al. (2015) An Investigation and Analysis of College Students' One-Nigth Stand. Health Medicine Research and Practice, 12, 11-14.

[29] Liu, Z., Li, X., Wei, P., et al. (2015) Influening Factors of Sexual Behavior among College Students in Nanjing. Chinese Journal of School Health, 36, 683-685.

[30] Yang, Y., Ye, Y., Yang, Y., et al. (2015) Prevalence of Bisexual Behavior among College Students. Chinese Journal of School Health, 397-398.

[31] Cardoso, F.L. (2010) Political and Sexual Attitudes Concerning Same-Sex Sexual Behavior. Sexuality \& Culture, 14, 306-326. http://dx.doi.org/10.1007/s12119-010-9076-8

[32] Lin, C., Huang, M., Zheng, J., et al. (2015) Concept and Attitude towards One-Night Stand of Different Gender University Students. The Chinese Journal of Human Sexuality, 24, 121-124.

[33] Glynn, J.R., Carael, M., Auvert, B., et al. (2001) Why Do Young Women Have a Much Higher Prevalence of HIV than Young Men? A Study in Kisumu, Kenya and Ndola, Zambia. AIDS, 15, S51-S60. http://dx.doi.org/10.1097/00002030-200108004-00006

[34] Chongqing MGO (2007) Preface of Chongqing. http://en.cq.gov.cn/AboutChongqing/2007/6/12/981922.shtml 